\title{
Poetricks: A Game to Engage Malaysian Secondary School ESL Learners in Understanding Poetry
}

\section{Angeline Ranjethamoney Vijayarajoo, Ariff Imran Anuar Yatim, Kuldip Kaur Maktiar Singh, Roslina Mohd Jani}

\author{
Academy of Language Studies \\ KM26 Jalan Lendu, 78000 Alor Gajah, Melaka, Malaysia \\ E-mail: \\ avijayarajoo@yahoo.com
}

Received: 15 January 2019

Accepted: 31 January 2019

Online First: 26 June 2019

\section{ABSTRACT}

Studying literature can be challenging for ESL learners. With the new cycle of poems introduced by the Ministry of Education in 2015, the teachers responded with great concerns over how to teach their students, who found poetry difficult and boring. Furthermore, the teachers found poetry less favourable compared to other literary genres. In order to fill the gap of a better understanding of the poems, in more engaging ways, the researchers designed a board game. The compulsory (new) poems for Forms Four and Five were used. 20 students and 40 teachers participated in this study. Data comprised the responses of the students and teachers, to the questionnaire and interview after the game. The game sessions were videotaped. The analysis of the data showed that the participants responded positively to the game. Hence, this game served as a supplementary tool in the teaching and learning of poetry in more engaging ways.

Keywords: literature, poetry, board game, language game 


\section{INTRODUCTION}

As English is a second language in this region, students grapple with grammar and communicating meaning due to the lack in language proficiency. Added to this setback is the learning and teaching of the literature component. The literature component was added to the English Language Syllabus in the year 2000. It was also 'tested' in the major government examinations in the years 2001 (lower secondary system) and 2002 (upper secondary system), bringing greater concerns to both teachers and students. This is the context of the current research.

\section{PROBLEM STATEMENT}

Studying literature is challenging for ESL students in schools especially when it is a compulsory component of the English Language curriculum. Students find it difficult and boring (Doris Boo and Navinder Kaur, 2000). The students have problems in terms of understanding literary devices, jargon and identifying with the foreign cultural context. Studies show that success in literature depends also on the activities employed to attract students. Students prefer interactive teaching and learning environment literature lessons (Tina Abdullah et al., 2007; Fauziah Ismail et al., 2008; Vasuthayan \& Kunaratnam, 2009) and interesting activities can foster love for literature. Moreover, students were also found to be passive in literature classrooms as lessons were teacher-centred (Sidhu, 2003; Suriya Kunmar, 2004). As such, there is a need to create interesting and fun activities such as board games which can make learning literature enjoyable.

\section{LITERATURE REVIEW}

The prose genre seemed to have been better received by teachers and students in comparison to the poetry genre. Wan Kamariah (2009) reported in her study that poems are not preferred because students were unable to understand, hence interpret, the figurative language found in literature. Students also found it difficult to understand the foreign contexts of the poems in the selection. Additionally, Wan Kamariah also stated that students had a negative attitude towards activities related to the memorisation of facts, drills and teacher-provided interpretations of the poems for the 
purpose of answering questions in tests. Sidhu (2003) claimed in her study that students found the literature class activities to be teacher-centred which were uninteresting and uninspiring as teachers seemed to focus on written work and preparing for the examinations. A study by Siti Norliana Ghazali et al. (2009) found that students do not like literature taught in classes, in particular poems, as these are considered challenging due to the difficult language. In keeping with these findings, Fauziah and Jamaluddin (2009) reported that student-centred activities created a better learning environment and developed students' motivation in literature. Hence, having studentcentred activities during literature lessons, such as a poetry board game, will not only be more interesting and enjoyable but also facilitate learning in an informal way. The next section shows how playing can facilitate learning without the formal and standardised ways of traditional teaching modes.

\section{LANGUAGE LEARNING AND THE USE OF GAMES}

Learning takes place through games and often children learn more before they begin school, when they have sufficient opportunities to play. Often with school, these games stop as performance and standard tests take precedence with their effects on learning. Gee (2003) claims that schools are in dilemma as to how to get young people to learn something that is challenging and to be able to enjoy it too. Perhaps schools should bring back games into the classrooms.

A group of panelists (experts on education) were optimistic about the promise of using games in pedagogy. Pea (2002), co-convener of a class and a professor in the Graduate School of Education, stated that 'gaming to learn' has been around Stanford for over a decade. Steinkuehler and King (2009) found that choice was critical for ultimate performance. Their research focus was on boys who were struggling to read and how they did a lot better if they could choose their texts to read and if the reading was via online games. This study also employed an innovative board game as they believed that games are architectures for engagement (Steinkuehler \& King, 2009). In other words, engagement was an important feature for learning to take place.

Similarly, Bauer (1995) remembered how his youth was filled with 
collaboratively building, taking risks and having fun while playing games. He also talked about variations in rewards, which he referred to as 'beyond simple star'. One way to achieve this was through better questions and more difficult tasks. In this study, the poetry board game had different types of questions with different levels of difficulty. Added to that was the variation in the reward and penalty system. The poetry cards had a simple reward and penalty system that is to either be able to proceed on the next round with a correct answer or to skip a turn if the answer was wrong. However, the 'Chance' cards were quite different as they gave students a chance to leap forward as a reward or alternatively, fall back with an incorrect answer. Thus, this game went 'beyond simple stars' which supported Bauer's (1995) belief.

Games also help to develop non-cognitive skills which are fundamental in explaining how we learn. Gee (2008) states that skills such as patience and discipline, which one should acquire as a child, happen when engaged in games. Hence, through games in the classroom, students are better prepared for both the cognitive and non-cognitive skills. The board game used in this study was found to develop these skills.

Motivation also plays an important role not only in engaging learners in any learning task, but also in ensuring that they are able to sustain their level of engagement until they are able to achieve a working knowledge of the specific task they are learning. Cohen (2010) stated that learners' motivation can be increased by employing methods that the learners respond positively to. It is therefore crucial for teachers to possess a wide methodological repertoire that they can use under different classroom environments and to students of different internal and external compositions.

According to Dörnyei (1998), motivation to learn a second language is both a highly challenging and intriguing affair due to the fact that the learners need to be encouraged to complete a particular language task. To this end, rewards are provided to keep these students interested. However, the teachers' ultimate aim is for the students to be motivated by the language learning tasks themselves as opposed to the rewards after the completion of the tasks. Therefore, finding the right balance between the learners' anticipation of rewards and the rewarding nature of a particular language learning task is of utmost importance in ensuring that the learners can be liberated from the extrinsic returns of a task. 


\section{THE THEORETICAL FRAMEWORK}

\section{Behaviourist Learning Theory}

Behaviourism and its roots can be traced back to the 1880 s and continues to be an ever-evolving theory that was developed by its proponents such as John Watson, Ivan Pavlov and B. F. Skinner (Weegar \& Pacis, 2012). According to Ertmer and Newby (2013), learning is perceived by behaviourists to occur when an appropriate response is observed after exposure to a specific stimulus. Behaviourists are therefore especially concerned with how the association between the stimulus and response is established, reinforced and maintained for the same desired outcome to recur.

In learning, the use of instructional cues, practice and reinforcement can be attributed to strategies recommended by behaviourists as a means to build and strengthen stimulus-response associations (Winn, 1990, as cited in Ertmer \& Newby, 2013). Language games of both traditional and digital varieties, in particular, employ positive and negative reinforcements that serve to provoke desired behaviours (Lepe-Salazar, 2015). These reinforcements help learners to remain motivated and emotionally invested in the language games that they play. In the poetry board game, the players are motivated to get to the finish line first. Hence, the need to get as many correct answers and the hopes and anticipation to get a 'Chance' card in order to make a leap forward. These then, enable the players to adopt strategies, within the stimulus-response associations, that would help them to realise their objectives.

\section{METHODOLOGY}

This paper is a case study involving 20 students and 40 teachers. The study involved qualitative and quantitative methods of analysis. Responses to the questionnaires filled by the participants and transcripts of the interviews with the participants, formed the bulk of the data for this study. All participants were briefed about the 'Poetricks' (Poetry Board Game) and its rules before they began to play it.

The 20 students were divided into five groups with four students in each group. Each student group was observed by four teachers. Hence, 20 
teachers played the role of observers, of the students playing the board game. The other 20 teachers were divided into five groups with four teachers in each group, just like the student groups, as they played the board game.

After the board game was over, the students and teachers in both groups - the ones who observed the students play, as well as the ones who played the game, filled out questionnaires and were interviewed the next day. The game sessions were also video recorded to be reviewed later to corroborate the responses in the questionnaires and the interview transcripts.

\section{Participants}

The study included 20 students and 40 teachers. The researcher asked the teachers of the school to select ten students with a good language proficiency and another ten with poor language proficiency. Out of the 40 teachers, 12 came from the school where the students were from, and the 28 other teachers came from five other schools nearby. The teachers were willing participants and had taught the subject for over ten years. The only set back was getting time to participate in this study, which they were able to manage as this study took place at the end of the school year, when all the examinations were over and there were very few formal activities going on in the school.

\section{Instruments}

The first instrument used in this study was a board game called 'Poetricks' (Poetry Board Game). This game was created by the researchers as an alternative to the conventional ways of teaching the literature component in schools. 'Poetricks' (Poetry Board Game) set comprises two boards which are namely the Level One and Level Two boards that cater for students of two different levels of proficiency. A total of four poems from the latest cycle of literary texts for Form Four and Form Five were used for this board game which are namely 'Charge of the Light Brigade', 'The Living Photograph', 'A Poison Tree' and 'What Has Happened to Lulu?'.

These poems provided the content for the questions on the cards. The players were required to answer the questions on the card whenever they landed on specific tiles along the board. The specific tile would have the 
label of one of the four poems, to which the participant who landed there would have to pick a card from the stack of that specific poem. If the answer was correct, the participant could proceed to the next round. Otherwise, the participant would skip a turn in the next round. In addition to the poetry cards, a set of 'Chance' cards were also created by the researchers.

The 'Chance' tiles also appear along the board at various points of the board. The reward and penalty system worked differently for the 'Chance' questions. Where the question was answered correctly, the players had the opportunities to move several steps forward, whereas an incorrect answer would result in a penalty of moving back a few steps. This is where the players have a good chance to reach the finish point on the board, at a quicker pace. Alternatively, they could take a longer time.

The board has a 'Start' and 'Finish' point. The first player to reach the 'Finish' tile on the board would be the winner for the session. The game is suitable to be played by four players at any one time. All of the sessions (students and teachers playing the board game, as well the teachers observing the students playing the game) were video-taped to facilitate the researchers' observation of the game being played in real time, and to be able to review the event at a later time with another unbiased researcher to minimise researcher bias.

The second instrument was the questionnaire for both, the students and teachers who participated in the game as shown in Appendix A and Appendix $B$ respectively. These questionnaires were perception-based questionnaires consisting of ten statements in which students are teachers were required to rate the statements across the five-point Likert Scale. The participants were asked to fill the questionnaires a day after they had finished playing 'Poetricks' (Poetry Board Game).

Finally, semi-structured interviews were also conducted by the researchers in order to allow the participants to reconstruct the details of their experiences while playing the board game, and to help triangulate the questionnaire and video data. The questions asked were built around the statements from the questionnaire. This is shown in Appendix D. The interview sessions also helped the researchers to get elaboration of ideas from all participants, which contributed to the rich, thick description of the data, pertaining to their responses to 'Poetricks' (Poetry Board Game). 


\section{FINDINGS}

The findings for this study were based on data collected from the questionnaires, interviews and video recordings of both, teachers and students while they were playing and observing the 'Poetricks' (Poetry Board Game) being played. Appendix C illustrates the overall results obtained from the questionnaires with the three groups of participants: The 20 students and 20 teachers who played the game and another 20 teachers who acted as observers and provided their responses after 'Poetricks' (Poetry Board Game) ended.

Appendix $\mathrm{C}$ indicates the responses in the questionnaire among the three groups of participants - the students who played the game, the teachers who played the game and the teachers who observed the students playing 'Poetricks' (Poetry Board Game).

Question 1 responses revealed that both the students and teachers enjoyed playing the game. Even the weaker language proficiency students enjoyed playing the game. The teachers who observed the students play the game also enjoyed watching the game.

Question 2 responses showed that 'Poetricks' (Poetry Board Game) helped the participants to understand the poems. This was seen in both the students and teachers who played the game and those who watched the students play the game.

Question 3 responses were specifically directed at the 'Chance' questions and showed that the participants found this exciting as well as a help in understanding the poems better.

Question 4 responses referred to the poetry questions and the majority of the participants found that these questions helped them to think about the poems more deeply. Question 5 was on motivation and the majority felt that the game was motivating and engaging.

Next, Question 6 was on whether the participants re-read the poems after the game. The majority responded that they did. Question 7 was an extension of Question 6, where the focus was on looking at more details 
during the re-reading of the poems, in looking for evidence to the answers. Though it can be said that the majority of the participants felt that they did, the students' responses to this was less than that of both the groups of the teachers. The student numbers were 15 out of 20 who strongly felt this but the teachers' numbers were 18 out of 20 for both groups - those who played the game and those who watched. This could be attributed to the fact that the students were new to the idea of checking out information on the poems on their own, compared to the teachers. This could also be because the teachers needed to be sure of the facts as they were teaching the poems to their students, and as teachers, they had to have the detailed knowledge.

Question 8 responses showed that the majority of the participants found the game exciting and challenging. This was seen more among the students $(20 / 20)$ compared to both groups of the teachers $(18 / 20)$.

Question 9 was about using 'Poetricks' (Poetry Board Game) in class and the majority responded positively to this (19/20 for the student group and 20/20 for both the teacher groups). Question 10 for the students was on the competitive spirit of the students and the majority responded that they became more competitive as they wanted to win the game. As for the teachers, the question was focused on the game as a useful teaching tool to use in the class, and the majority in both teacher groups responded positively to this $(20 / 20$ and $19 / 20)$.

In summary, it can be concluded from the responses in the questionnaire that 'Poetricks' (Poetry Board Game) was well received by the students and teachers alike. All the responses from the 20 participants of each group were either in 'agreement' or in 'strong agreement' of using 'Poetricks' (Poetry Board Game), echoing their positive feelings towards the game.

The second part of the data came from the semi-structured interviews which yielded results on a deeper level. The interview questions were worked around the statements found in the questionnaire. The purpose was to get elaboration of the participants' responses. The questions for the semi-structured interview are found in Appendix D.

The first question was on the feelings the participants had as they began playing the game. Both, the students and teachers confirmed that 
they were excited to play the game. The observing teachers said that they looked forward to the game and wished that they played the game, rather than just observe the students playing.

The second question was if and how 'Poetricks' (Poetry Board Game) helped the participants. All the participants said that the board game helped them, as they looked for answers and re-read the poems in order to find the answer. Below is an answer from a student from a good proficiency level class,

"The game got me to re-visit the poem several times and in looking for the right answer, I realised that I knew the answers to the other questions but not the question that I had to answer ... that was unfortunate.... and I wished that it was my turn to answer the questions which I knew."

This showed that learning was taking place. The next excerpt is from an answer from a student in a lower proficiency-level class,

"I like... I look at poem, sometimes get answer, sometimes no. When no, I see answer card, and then I know."

This was also a case of learning, where wrong answers led to the answer card and the students would pay attention in case the game continued and the cards went another round.

The third question in the questionnaire was on the 'Chance' questions. The students and teachers looked forward to this tile as the reward system was far greater than the ordinary poetry question tile. The participants hoped to land on a 'Chance' tile but they were also worried if they could not answer the question, as they would face a penalty that could leave them worse than before. Sample responses from the three groups included:

Students:

"I like but frighten also. Want to reach the end fast fast... Sometimes okay, sometimes not okay."

Teachers who played the game: 
"The 'Chance' questions were exciting as we wanted to go ahead quickly in order to get to the finish line. The questions also challenged us, if we knew the answers or not."

Teachers who observed the students playing the game:

"Actually, we wished we were playing. Half the excitement was taken away from us as we could only watch and not say anything. We wish there were enough board games for us to play as well. Yes-lah, the 'Chance'questions were like a chance to win or lose. There was no draw."

Question 4 was on whether the participants gave any thought about the poems during or after the game. The majority of the participants said that they did. Some responses from them:

Students:

"Sometimes think, sometimes forget. Mostly if play the game tomorrow, sure think, think, think. Maybe we play game more. Better than just listen to teacher."

Teachers who played the game:

"The game was an eye opener for me. I thought of the poems more deeply. I wondered what could have caused the conflict between Lulu and her mother. Also, I wondered where the father was. I would find out more and pose these questions to my students."

Teachers who watched the students play the game:

"I thought of the poems and some of the questions. From there, my thoughts went to other areas connected to the questions. I found that the questions triggered other thoughts and ideas for me to work on as I began to teach the poems."

These responses show that the students found the game a more interesting alternative to just listening to the teacher teach in a lecture-style mode. The teachers found the game a trigger to further their explorations on their 
own understanding and how they could bring a larger understanding of the poems, through the initial questions in 'Poetricks' (Poetry Board Game). This went into the area of pedagogy and their own learning process.

Question 5 was on how the participants found 'Poetricks' (Poetry Board Game). Some said it was exciting, others said it was fun and motivating for them. Some responses appear in the excerpts below:

Students:

"The game made me want to know more about the poem."

Teachers who played the game:

"The game was different - nothing of this has been in store for us. Very refreshing."

Teachers who watched the students play the game:

"The game was exciting for everybody else except us.... ok ok... we were excited but we wished we were playing too."

Question 6was on whether the participants re-read the poems later. All the participants said that they did except that some of the students mentioned only re-reading the parts that appeared in the questions. As for the teachers, their re-reading confirmed and added knowledge for them as individuals and to be better equipped as teachers to teach the poems to their students.

Responses to Question 7 and 6 were similar, with the difference that some students and teachers, looked for more evidence to strengthen the answers while many re-read the poems to check if the answer given in the answer card was correct.

Question 8 was on how the participants felt during the game and again, the majority mentioned, 'excited, a bit nervous if cannot answer, want to win'.

Question 9 was on whether the participants would consider the game for class. The majority sai,'Yes, surely, better than reading and reading...' 
Question 10, to the students, was on their motives of playing the game. The majority of the students answered 'to win the game'. The question to the teachers was if they considered 'Poetricks' (Poetry Board Game) to be a useful tool and resource in their teaching. The answer was in the affirmative, unanimously.

In summary, it can be concluded from the responses to the semistructured interview, that all the three groups - the students playing 'Poetricks' (Poetry Board Game), the teachers playing it and the teachers observing the game, enjoyed the playing the game and to some extent, watching the game being played. In fact, the teachers who were observing the students play the game voiced out their disappointment in not playing the game. More than the enjoyment of the game, learning was evident in all the three groups. The participants learnt and remembered new facts, they re-read the poems to check, confirm or add to their existing knowledge while considering the game as an alternative classroom activity.

The researcher noted that the participants enjoyed playing the game, were engaged and alert throughout the game. Another researcher was asked to view the video tape and some of her jottings included: "participants engaged, interaction going on, motivation to get to the 'Finish' tile, disappointment at wrong answers, great shrieks of joy when own answers correct, similar joy expressed when other players got answers wrong, competitive spirit, alert, took time to answer, a lot of noise...."

\section{DISCUSSIONS}

The main aim of this study was to gather responses from both, the students and teachers on 'Poetricks' (Poetry Board Game) as an additional resource for teaching and learning in classrooms. This was especially important due to the context of change - the introduction of the new cycle of literary texts. As mentioned earlier in the literature review, poetry is one of the least liked literary genres. As a result, the researchers worked round this genre by creating a board game.

The sources of data show that 'Poetricks' (Poetry Board Game) was well received and even enjoyable to all the participants. The teachers who 
were observers were sorry that they did not get to play the game. One of the limitations of the research was the lack of 'Poetricks' (Poetry Board Game) sets, thus a constraint to include more students to participate in the game.

Some of the highlights of 'Poetricks' (Poetry Board Game) is the fact of the two different levels in the board game; one, for the more language proficient students and the other, for the less language proficient student. In this way, teachers could help the weaker students to gain confidence by playing level 1 before moving on to level 2. Even if the students could not play level 2, the fact that they are not excluded, and can still play the level 1 game, would be a learning experience for them.

Apart from the two different levels of the board game (which had questions of differing levels of difficulty in terms of language), the types of questions were varied. The question types were objective, fill in the blanks and subjective in nature. Such variations allow for space for the students to tackle questions within their ability as well, before moving on. Such questions also took away the routine in questions. Added to this was the fact that the Answers were provided in the Answer cards. Hence, this poetry board game served as a self-access learning cum teaching tool.

The 'Chance' questions provided a different and radical system of rewards and penalties. Hence, the 'Chance' questions posed a challenge to the participants - to make it quicker to the finish and win the game, or to go back and reduce the chance to win. This was an attraction in the game - for both, the students and the teachers.

In summary, the data showed that all the participants welcomed 'Poetricks' (Poetry Board Game) as a learning and teaching tool, which was engaging, interactive, fun and something that has never been done in literature in the past, more so, in the poetry genre.

The rewards and penalties that the students received after every correct or incorrect response to a question instilled the competitive edge within them. In addition, the two differing levels found in the game set ensured that the students had the opportunity to play it at levels suited to their language proficiency and comprehension of the poetry selections. Meanwhile, for the teachers, they now felt that they had an additional tool 
to the conventional teaching methods that they employed when teaching the literature component. This game, to them was a 'supplement' to the formal lessons and at the same time, resulted in a high level of engagement among the students. It may not replace formal lessons as the sole source of understanding and appreciating poetry but would serve as an additional educational tool that can assist students and teachers in the learning and teaching process of the literature component, mainly, poetry.

Having said that, future research should look at how the Poetry Board Game has brought about measurable changes. This can be translated to the tests and examinations and is worth further research. A pre and post-test could be administered to students, before and after the engagement with the game. This would be another direction of this study.

\section{CONCLUSION}

This case study of 'Poetricks' (Poetry Board Game) and the feedback received from the participants shows that there is an additional and supplementary way of teaching and learning the literature component, for teachers and students in schools. This game zeroes in on the poetry genre, which is least liked by students. The game is also self-access as it comes with the answers in the answer cards. Teachers and educators are constantly looking for innovative ways to teach literature texts in order to engage their students in a fun way. Therefore, this poetry board game, with the necessary elements of learning in a more conducive environment, can provide a muchneeded variety. The next direction of this study would be to measure the improvement of students' performances in actual testing and evaluation. This could be in terms of a pre and post-test as mentioned above.

\section{REFERENCES}

Bauer, M.I. \& Bonnie, J.E. (1995). Modelling time-constrained learning in a highly interactive task. In Katz, Irvin R., Mack, Robert L., Marks, Linn, Rosson, Mary Beth. Nielsen, Jakob (eds.) Proceedings of the ACMCHI95 Human Factors in Computing Systems Conference, May 7-11, 1995, Denver, Colorado, pp.19-26. Retrieved from http://www. acm.org/sigchi95/proceedings/papers/mib_bdy.htm 
Cohen, A.D. (2010). Focus on the language learners: Styles, strategies and motivation. In Schmitt, N. (ed.) Applied linguistics ( $2^{\text {nd }}$ ed.). London: Hodder \& Stoughton.

Doris Boo \& Navinder Kaur (2000). The Literature Component in English, Form Four. Bangi: Pelangi Sdn. Bhd.

Dörnyei, Zolt'n (1998). Motivation in second and foreign language learning. Language Teaching, 31(3), pp 117135 doi:10.1017/ $\mathrm{S} 026144480001315 \mathrm{X}$

Ertmer, P.A. \& Newby, T.J.(2013). Behaviorism, cognitivism, constructivism: Comparing critical features from an instructional design perspective. Retrieved August 5, 2016 from https:/www.uwplatt.edu/files/ttc/ idarticle.pdf

Fauziah Ahmad \& Jamaluddin Aziz (2009). Students' perception of the teachers' teaching of literature communicating and understanding through the eyes of the audience. European Journal of Social Sciences, $7(3), 17-26$.

Fauziah Ismail, Marzilah Abdul Aziz \& Tina Abdullah(2008), Literature in English language teaching:A revisit in the Malaysia context. In Noor Abidah Mohd Omar dan Zaidah Zainal (ed.), Research in English Language Teaching. Kuala Lumpur: UTM Press.

Gee, J.P. (2003): What video games have to teach us about learning and literacy. Computers in Entertainment, 1(1), 20. http://doi.acm. org/10.1145/950566.950595

Gee, J.P. (2008): What's a screen mean in a video game? Paper presented at Proceedings of ACM IDC08 Interaction Design and Children 2008, pp.06. http://doi.acm.org/10.1145/1463689.1463698.

Gurnam Kaur, S.(2003). Literature in the language classroom: Seeing through the eyes of learners. In Ganakumaran, S. \& Edwin, M. (eds.). Teaching of Literature in ESL/EFL Contexts. Petaling Jaya: Sasbadi Sdn. Bhd. 
Lepe-Salazar, F. (2015, November). A model to analyze and design educational games with pedagogical foundations. Paper presented at the $12^{\text {th }}$ International Conference on Advances in Computer Entertainment Technology, Iskandar Malaysia. http://dx.doi. org/10.1145/2832932.2832951

Pea, R. D. (2002). Learning science through collaborative visualization over the Internet. In N. Ringertz (Ed.), Nobel Symposium: Virtual Museums and Public Understanding of Science and Culture. Stockholm, Sweden: Nobel Academy Press.

Siti Norliana Ghazali, Roszainora Setia, Chittra Muthusamy \& Kamaruzaman Jusoff (2009), ESL student's attitude towards texts and teaching methods used in literature classes. English Language Teaching, 2(4), 51-56.

Steinkuehler, C. \& King, E. (2009). Digital literacies for the disengaged: Creating after school contexts to support boys' game-based literacy skills. On the Horizon, 17(1), 47-59, 2009. DOI 10.1108/10748120910936144

Suriya Kumar, S. (2004). A study of the motivational factors that influence the learning of literature among upper secondary school students in Negeri Sembilan. M.A. Practicum Report. Bangi: Universiti Kebangsaan Malaysia.

Tina, A., Mohammad, H.Z., Fauziah, I., Fara, A. \& Marzilah, A.Z. (2007). A new teaching model to teach literature for the TESL pre-training service programe in Universiti Teknologi Malaysia. Retrieved on August 15, 2016 from http://eprints.utm.my/3970/1/75167.pdf

Vasuthavan, E. \& Kunaratnam, S. (2009). Teaching poetry to reluctant learners in a Form Four ESL classroom. Paper presented at Proceeding of $2^{\text {nd }}$ International Conference on Teaching and Learning (ICTL 2009), INTI University College.

Wan Kamariah Baba (2009). An investigation into teachers' and students' attitudes towards literature and its use in ESL classrooms: A case study at matriculation centre in Malaysia. Unpublished PhD Thesis, University of Leicester. 
Weegar, M. A. \& Pacis, D. (2012). A comparison of two theories of learning - Behaviourism and constructivism as applied to face-to-face and online learning. E-Leader International Journal, 7(1), 1-20. Retrieved on August 15, 2016 from http://www.g-casa.com/conferences/manila/ papers/Weegar.pdf

Winn, W. (1990). Some implications of cognitive theory for instructional design. Instructional Science, 19(1), 53-69. 